pression. The nurses are most carefully uniformed, with different kinds of caps showing the different grades, different ribbon bands, etc., and, alas, the uniforms are lamentable. The junior nurses wear a linen supposed to be white. It is, instead, the sad, hopeless gray of badly laundered hospital sheets. The dresses are made with much fulness, big linen squares tied on for aprons, and these of the most disheartening grime. The caps are not plain and simple, like the unassuming but spotless linen of the German sisters. They are flimsy, coquettish, elaborate, with velvet or ribbon bands, small, perched upon untidy hair, and so dirty that they are funny. Altogether the impression is quite indescribable. The "surveillantes," who wear a dark-colored dress, look much better, although still far from the ideal. Many of the younger nurses one sees have a callous expression and a flippant manner; then, on the contrary, one meets quite frequently rather older women who give one a cheering impression of character, worth, and ability. I was told in one of the hospitals by a young physician that striking improvements in the nursing staff had taken place in the last two years.

The classification of the nurses was something I did not get straight, but those who take the training appear to be distinguished from the others by a special title. The "surveillantes," or supervising nurses, are in five classes. The "matron" of the English hospitals, or the superintendent of nurses of ours, is conspicuous by her absence, and no one realizes what she is to a hospital until one visits hospitals where she is not. To her non-existence I attribute all the chilly unhomelikeness, lack of "atmosphere," and general dreariness that one finds in many of these big European barracks of hospitals, some of which look no pleasanter to live in than if they were so many clinical laboratories. The old Hotel Dieu is one of the dreariest of all. It is one of two which still retain the Sisters of Charity, owing, I believe, to some clause in its constitution. The statues of Bishop Landry and two of the early French kings stand near the entrance, and they certainly have not been dusted in fifty years.

The Boucicaut, which is a very beautiful pavilion hospital, was built not long ago by private benevolence and placed under the management of the city.

(To be continued.)

\title{
THE ENGLISH REGISTRATION MOVEMENT
}

THE Select Committee have recently heard some strong testimony in favor of registration. Mrs. Bedford Fenwick gave an outline of the entire movement from the time of founding the Royal British Nurses' Association in $\mathbf{1 8 8 7}$ to establish it. She showed what had been done in 
South Africa and in New Zealand, and reported the excellent effect of these acts, especially that of New Zealand, which is much the best. She gave a strong statement of the whole evolution of conditions from the educational standpoint, and made a special plea for justice to trained nurses as a valuable class of public workers. After reading a general statement which refuted the arguments of the opposition she handed in a synopsis of nearly one hundred cases in which women described as nurses and engaged in nursing had appeared in the courts for criminal offences varying from murder to petty thefts. While these criminals may not actually have been nurses, yet trained nurses have to endure the odium and ignominy of such proceeding. She also handed in a statement prepared by the State Registration Society, representing fifteen hundred matrons and nurses, and a list of eighteen hundred medical practitioners, nurses, matrons, and public persons in favor of registration, with copies of all resolutions passed by public bodies in favor of it. Her entire mass of material was strong, complete, and irrefutable, and meant a tremendous amount of hard work.

Several prominent physicians have also testified in most emphatic and positive terms for registration. Sir James Crichton Browne, Sir Victor Horsley, Dr. Bezly Thorne, and Dr. Langley Browne have given excellent testimony, and, although they have only told the Select Committee exactly the same things that the nurses have told them, the Select Committee heard them with much more respect and deference. So preponderatingly strong has the whole registration evidence been so far, that it seems hardly possible it can be ignored. One feels that it must be accepted. If it is not, the explanation will lie chiefly in the strange indifference to education which keeps England back in lines where the worker needs to be fitted for the work, and in the preponderance of sentimentality over a sense of justice among masculine beings.

However it turns out, the organized nurses of Great Britain and Ireland have made a magnificent campaign of education and have shown courage, energy, and persistence which must excite general admiration. No one will ever know how much hard work it has all meant except those who have gone through similar trials.

L. L. D.

\section{ITEMS}

Dr. Doutr, writing to the Lancet, thinks that cases of syphilis should be reported to health boards and general measures taken against this disease. He is of the opinion that if syphilis and gonorrhoea could be stamped out, phthisis and infantile tuberculosis, kidney disease, gynæcological disorders, bone, eye, ear, skin, brain, spinal-cord diseases and, 